\title{
“LOW-TECHNOLOGY”: A FORGOTTEN SECTOR IN INNOVATION POLICY
}

\author{
Prof. Dr. Hartmut Hirsch-Kreinsen
}

\begin{abstract}
In the discussions on research and technology policy focuses mainly on the dynamic innovation of new technologies. Long term growth, competitive advantages on the world market and employment effects are primarily perceived in new high-tech products. According to this perspective the question as to the future of industrial sectors that produce mature and conventional standard products is not raised at all. Such industrial sectors are, following well-known OECD categories, regarded as "low-tech". However, there are a number of convincing examples of sectors and companies that have been successfully innovating low tech products in "high-tech countries" of the European Union. The paper focuses on low-tech companies analysing their innovative capabilities and developmental perspectives. The argumentation is based on results of a recently finished research project on the developmental perspectives of low-tech industries funded by the European Commission (project title:"Policy and Innovation in Low-tech Industries in Europe - PILOT“).
\end{abstract}

Keywords: low-technology, industrial innovations, innovation system, industrial development

\footnotetext{
* Prof. Dr. Hartmut Hirsch-Kreinsen

Chair of Economic and Industrial Sociology

Faculty for Economics and Social Sciences

University of Dortmund

D-4422I Dortmund

h.hirsch-kreinsen@tu-dortmund.de
} 


\section{Introduction}

In the public-political and scientific debate, the societal development perspective has for some time been subsumed under the term 'knowledge society'. The debate proceeds on the assumption that the knowledge society is largely based on scientific knowledge, new technologies and high-tech innovations while only secondary importance is attached to the role of traditional economic sectors for the future social and economic development. The prevalent opinion is that high-tech industries are the key to future growth and employment and that research and innovation policy actors are thus well-advised to promote such industries. It is by no means the intention of this paper to deny that science and research as well as especially high technologies play a crucial role for the future economic and social development in developed countries of the European Union and that therefore the scientific as well as the public-political interest in them is very understandable. But at the same time it should not be forgot-ten that this outlook is accompanied by an inadmissible narrowing of the perspective with the result that the industrial and technological development potentials of industries not based on high-tech are overlooked and possibly misjudged.

A first indication that this is the case, is data showing the surprisingly high quantitative import of these industries. This fact can be demonstrated more specifically if one reverts to the $R \& D$ intensity, a common indicator that is used internationally to measure the ratio of the R\&D expenditure to the turnover of a company or a business sector. ${ }^{1}$ According to OECD categories, the industrial sectors can be classified as follows: Hightechnology sectors ("high-tech") with a R\&D intensity or more than $5 \%$, sectors with complex technology ("medium-hightech") with a R\&D intensity between $3 \%$ and $5 \%$. Industries which are not research-intensive ("medium-low-tech" and "low-tech") have a R\&D intensity below 3 percent. They are here referred to together as "low-tech" and "medium-lowtech" (LMT). Pharmaceuticals, the electronic industry, vehicle construction, the aerospace construction industry as well as mechanical engineering, for instance, are categorised as hightech. "More mature" industries such as the manufacture of household appliances, the food industry, the paper, publishing and print industry, the wood and furniture industry and the manufacture of metal products -such as the foundry industry- as well as the manufacture of plastic products are regarded as LMT.

According to the R\&D intensity indicator, it appears that the
LMT industries play a very important role in employment in all industrialised countries. Referring to data concerning the EU I 5 countries in 2005 LMT industries account, roughly speaking, for over 60 percent of employment in the whole manufacturing sector whereas the share of high-tech industries is about 10 percent $^{2}$. Referring to data from II OECD countries it can also be shown that there has been a tendency for the low-tech industries' share of manufacturing to decline during the long period since 1980, while the share of high-tech industries has increased.A similar trend can be observed regarding the share of value added of the different sectors in manufacturing. In the long run, starting from a low level, high-tech sectors show a rising share of the value added in manufacturing while the share of the LMT sectors is declining. However, these declines are not marked, and the LMT industries still constitute by far the largest part of the manufacturing sector in OECD economies. It is debatable whether there is a real structural change in the period examined here. In fact, the LMT sector continue to evince remarkable stability and a high share of employment (cf. Kaloudis et al., 2005).

Further evidence for the importance of this sector is provided by a number of empirical findings which emphasise the innovation ability of the low-tech sector precisely also in high-tech countries (cf. Maskell, 1998; Schmierl, 2000; Palmberg, 200 I;Tunzelmann and Acha, 2005); thus the Economist, for instance, referred to "the strange life" of low-tech industries in the high-tech state California several years ago (The Economist, 1998). Hence, the thesis is: "Innovation in low-tech industries should, therefore, not be seen as a contradiction in terms." (Mendonça and Tunzelmann, 2004, p. 15).

I would like to follow up these findings in the following. It will be asked which innovation potentials LMT sectors really have, which conditions foster these potentials and which conclusions innovation policy can draw from these findings. The focus will be on technological innovations that are directed at the development and marketing of improved products and at the introduction of new production structures such as technical-organisational methods of production and logistical activities (OECD, 1997: 10). 44 case studies conducted in low-tech businesses from $9 \mathrm{EU}$ countries with, as a general rule, between 500 and 50 employees, form the empirical basis for this investigation. More than half of the examined companies come from the sector metal products, the rest come from the sectors food and stimulants, wood products, textiles, clothing, leather, leather goods as well as paper, publishing and print products. The case studies were conducted

I This indicator covers in-house R\&D expenditures for R\&D staff, further R\&D costs and investments as well as out-house expenditures for, e.g., R\&D tasks assigned to other companies and organisations (OECD, 2002, p. 108).

2 Own approximation based on: OECD Science, Technology and Industry Scoreboard 2005, Annex A, p. I83, Eurostat Database 2005 
in the period from summer 2003 to summer 2004 in the in the context of an international research project with the title "Policy and Innovation in Low-Tech - PILOT“3.

\section{I.Typical innovative LMT companies}

If one recapitulates the research findings, different types of LMT companies can be differentiated in terms of the primary subject area and the objective target of their innovation activities 4 .

(I) There are a number of enterprises which mainly proceed in small steps when further developing their given products. Individual components are improved and changed with regard to their material, their function and quality but the structure and the technological principles of the products remain unchanged. This type of company can be characterised as standard manufacturer. To cite some examples, enterprises with products for relatively stable market segments, such as a producer of metal parts for special applications, or enterprises that manufacture products for partly also internationally active major customers - as it were as "extended workbenches"- belong to this type. In many cases their products are more or less technologically mature, often they are standard parts made of cheap materials, they are made in big production runs and are characterised by low complexity.

A special case that can be regarded as belonging to this field, is a company type which one can characterise as simple producer. An example for this type is a producer of simple electric heating elements for industrial applications, whose products have hardly been developed further in the past few years, at the most as regards their material quality. These products are manufactured within the scope of relatively labour-intensive processes with a restrictive activity layout. This type of enterprise denotes a "bottom" segment of low-tech that is very difficult to circumscribe. It stands under particular cost and competition pressure and its products are easily imitable.

(2) Alongside these companies, there are companies which with varying scopes and temporal cycles- directly promote market-induced product innovations in order to open up new sales opportunities in a highly flexible manner.This involves, for instance, a fashion-oriented design of products, the functional and technical upgrading of products, a rapid response to changing customer wishes, taking advantage of market niches, skil- ful branding strategies and the expansion of service activities and product-related service activities. In this context, not only company from the textile and clothing industry must be mentioned but also, for instance, businesses from the furniture and leather goods manufacture whose product development is geared to anticipatable fashion cycles and whose existing product lines demand a more or less continuous variation. A typical example in this respect is an office furniture manufacturer who at very short notice accepted the order of a big retailer with much market power for a large number of (to be speedily supplied) office furniture of a new, not previously produced variant and who correspondingly varied his products. Due to the augmented number of product variants and individual components, it became necessary to use a very modern high bay racking system in this company to be able to manage the drastically increased number of product components. In various other cases we could also observe an augmentation of the range of products which were supplemented with a range of product-related services and logistics services tailored for certain customers. According to the available empirical findings, such direct and specific customer-related innovation activities are gaining in importance for many of the low-tech companies. In a nutshell, this type can therefore be characterised as serviceoriented company.

(3) One has to distinguish between product-related and process-related innovations.Although it is often difficult to separate both aspects empirically, as a product innovation often calls for changed process structures, there is, however, a whole series of companies whose innovation endeavours are primarily directed at their processes. Especially businesses that manufacture comparatively simple products often direct their innovation endeavours at the introduction of the most modern process technologies. This type of company can be characterised as a process specialist. An especially instructive case in this respect is the manufacture of very easily imitable, cheap and simple sealing rings based on highly complex process technologies and the newest materials. Its process competencies lie in the hands of a few technicians and engineers from the management. A further example in this regard is the continuous further development of process performance and process precision as observable, for instance, in woodworking. It has reached a level of technical achievement which, according to the experts, has so far not been equaled in any other production technology and is considered a pacesetter for further technical developments. Similar trends could also be studied in sheet forming companies and firms manufacturing plastic parts or mechanic

\footnotetext{
3 The project is discussed in more detail in Hirsch-Kreinsen et al., 2006; see also www.pilot-project.org. For a more general discussion of the low-tech issue see: Hirsch-Kreinsen and Jacobson, 2008.

${ }^{4}$ It need not be emphasised that this typing involves analytical exaggeration. In reality, the different types can overlap.
} 
components. Another example is a paper manufacturer who continually optimises his elaborate processes. Quasi as a byproduct, he therewith also obtains an improvement and alteration of the product quality. Apart from processes with a high technological level and automation degree, this enterprise type also encompasses processes with relatively simple standard techniques. Thus, one metal company downright strategically pursued a concept of employing low-budget technologies. In various cases one can also speak of a coexistence of complex and standardised process technologies in one and the same business. Generally, however, it must be noted that many of the examined LMT companies operate on the basis of high-tech production technologies. Strictly speaking, their labelling as lowtech is more than misleading.

If one compares the significance of the different types of company on the basis of the results of the case studies, one can summarise the following facts: No indication could be found that LMT companies mainly produce simple mass products like the aforedescribed simple producer. Much more frequently they seem to be flexible producers of customised quality parts and of increasingly complex products. In most cases, companies are strategically enlarging the share of complex and customised products in relation to their whole range of products as a specific strategy of competing with companies from low cost countries. Particularly logistic-related technologies will play an increasing role in future. While this holds true for nearly all sectors and industries, it is even more important for low-tech sectors. As indicated, the main reasons for this are the integration of the companies into larger value chains as well as particularly the chances which the improved and flexible ability to supply open up.

Following on from categories taken from innovation studies (Henderson and Clark, 1990), one can sum up that the innovation activities of the companies move within a spectrum that is, on the one hand, bounded by the type "incremental" innovation and, on the other hand, by the type "architectural" innovation. Both types have in common that they use given technologies and continuously develop these further.They thus differ fundamentally from "radical" innovations which leave given technological development paths and devaluate them. Incremental innovations restrict themselves to advancing given technological concepts step-by-step, for instance, by improving the individual components of a specific product design. The term architectural innovation, however, denotes the continual recombination of existing components to obtain a new product design or a new process structure. This can by all means entail the alteration or improvement of individual components but all in all the well-rehearsed technological development path is not abandoned. In reality, the boundary between both innovation types is blurred. In a nutshell, it can be asserted that a big and possibly growing significance for the low-tech sector inheres in architectural innovations. This is obviously true largely independent of differences between and specific conditions of the various industrial sectors (Palmberg, 200I). The reason is the distinct competition which these companies face and which they can quite obviously only cope with by taking pains to initiate technological innovations in a manner feasible and typical for them.

\section{Preconditions for LMT innovativeness}

If one wishes to analyse the requirements and preconditions for the innovation ability of low-tech companies more closely, it is first of all necessary to clarify the specific structural conditions of these firms. These can be characterised relatively precisely by taking recourse to the R\&D intensity indicator. The companies only have limited or no independent R\&D capacities at all and their in-house expenditures for, e.g., R\&D personnel and costs and investments connected with R\&D activities are low. Their outside spending on R\&D orders to other companies or organisations is likewise small. One can therefore assume that these firms have other kinds of resources and capacities to act, on which their innovation ability is founded and which (functionally) compensate for their lacking R\&D capacities (Palmberg, 200I: 67).

Resource-oriented analysis concepts of innovation and management research (e.g. Penrose, 1959; Foss, 1997) lend themselves well for attempts to specify the above-mentioned connections. These concepts aim at examining how firms attain competitive and innovative advantages, which resources they have at their disposal in this connection and furthermore how they employ their resources. Putting it simply, the central argument in this case is that companies can be characterised by means of their specific combination of more or less special and rare resources, especially of knowledge in miscellaneous forms, and that they must in each case dispose of a specific competency to be able to make use of these resources for their strategic goals. This leads to the question concerning the prevailing knowledge base of LMT companies.

\section{I Knowledge Base}

In a general perspective, the knowledge relevant for low-tech firms can be conceived as practical knowledge. Unlike scientific knowledge that orients itself on criteria such as theoretical relevance and universality, validity criteria such as practicability, functionality, efficiency and failure-free use play a decisive role for practical knowledge. It is generated in work process-related contexts and its probation rules are determined by the respective application and utilisation context. Practical knowledge comprises both explicit, codified and formalised knowledge ele- 
ments such as, for example, design drawing and requirement specifications for new products and technical and engineering standard knowledge as well as, above all, implicit elements. The latter are intimately connected with everyday experience and processes of "learning by doing" and "learning by using" which constitute a typical form of practical knowledge acquisition ${ }^{5}$. On that score, particularly the never completely anticipatable conditions under which the products and technical systems are developed and used must be taken into account: the complexity and contingency of the material, social and economic factors of the usage situation and the imponderabilities of possibly intricate technical systems. Often experience, even sure instinct, seldomly -or only with great effort- explicable, are essential for their use.

However, practical knowledge cannot always be distinguished from scientifically generated knowledge. As shown by some case studies, it is in many ways closely entwined with the systematic use of scientifically generated knowledge to enable the persons concerned to come to terms with specific development problems. An example one frequently comes across in this regard, is the introduction of new production technologies for the optimisation of ongoing production processes. The adaptation procedures which are usually required when installing the purchased equipment or the ex ante specification for systems to be constructed in an application-oriented manner, are both to a large degree based on the accumulated practical knowledge of the respective user company, concretely on the experience-saturated guidelines of the management and further technically adept persons. As particularly process specialists show, scientific knowledge and new technologies are indeed indispensable for low-tech innovations but they are always resorted to in a targeted and selective way to solve practical innovation problems. ${ }^{6}$

All in all, the different knowledge elements in the individual firms converge into a specific industrial competence in each case -also labelled as "core competence" in management literature (cf. Prahalad and Hamel, 1990)-, which can be regarded as a central requirement for the equally specific innovation capability of the companies. As the results of the case studies exemplify, this specific competence encompasses:

- The ability to handle specific product materials in a systematic manner, as in the case of the development and procedural handling of particular steel alloys with the objective of advancing especially durable products such as pipes; generally spoken, this ability mostly characterises companies of the type of the standard manufacturer;

- The know-how and the experience to ensure the failurefree employment of complex production lines and their constant enhancement as, for instance, in the case of the production of simple sealing rings and the production of household fuses; this ability mostly characterises companies of the aforementioned type of the process specialist;

- The control over the process chain and logistics as prerequisite for a stronger market orientation as well as the flexibility of the operating processes which was, for instance, found to be particularly pronounced in the case of the production and distribution of office furniture; this ability is very often a feature of the type of a service-oriented company.

\subsection{Knowledge Carriers and Dissemination of Knowledge}

If one enquires about the knowledge carriers and the dissemination of individual essential elements of knowledge, the findings reveal that the innovations mostly take place in the context of the operative processes and that they are possibly initiated and at any rate pressed ahead with by the staff responsible for the ongoing functions, such as engineers, technicians, master craftsmen and qualified workers. Innovation impulses often also emanate from specialised departments such as management, quality assurance and the construction department which often only exists in a rudimentary form in the small and medium companies investigated. This, for example, applies to process innovations which entail the stepwise introduction of new production and logistics techniques under the direction of the respective management and also occasionally with the active participation of the production personnel. Often the trouble-free introduction of modern systems and their subsequent efficient operation are largely dependent on the qualification, willingness to perform and motivation of the blue-collar workers on the shop-floor too. Furthermore it is not uncommon to observe cases, in which the innovation ideas are the result of accidental trial and error processes or even often originate from individual technicians, managers or the proprietors. This situation prevails especially in smaller, person-centred and little structured firms with only limited management capacities. Moreover, the growing importance of market-induced innovation impulses, which are generally taken up by the sales and marketing personnel and communicated into the companies, must be taken into account.

\footnotetext{
5 Practical knowledge includes "the vital elements of user experience of operation; shopfloor experience of construction or production; and 'rules of thumb' from previous design experience." (Faulkner et al., 1995, p. 220).

${ }^{6}$ As innovation research shows, this is by all means a typical case of technical innovation, whereby R\&D and science do not give the impulses but conversely react to practical problems (e.g. Kline and Rosenberg, 1986).
} 
As the aforesaid already indicates, the acquisition and generation of innovation knowledge by no means only takes place within the company, rather external knowledge sources prove to be exceedingly relevant. In almost all of the examined companies, the knowledge of other firms, organisations and other actors as well as its systematic use for the respective innovation measures plays a decisive role. One can speak of a distributed knowledge base which encompasses actors who are independent of each other and who often come from different branches of trade and technology fields (Cf. Roberston and Smith, 2008). All empirical findings suggest that the main source for the knowledge generation of the LMT companies lies here. In this regard, a particularly important role is played by the sales market and the customers. They do not only, as described above, trigger customer-oriented product innovations but also process innovations such as the corresponding layout of storage and logistics systems. In addition, especially suppliers from different walks of business play a more or less influential role in the context of the distributed knowledge base:

In the context of process innovations conducted by process specialists, an important but indeed varying role pertains to the manufacturers and suppliers of technical equipment and systems in almost all of the examined cases. On the one hand, the low-tech companies install standard systems which can be purchased ready-to-use. On the other hand, technical systems are custom-designed, or at least certain components and functions are adapted to the particular user needs. Naturally this presupposes relatively close co-ordination, communication and learning processes between the partners concerned. In many others of the examined companies, the suppliers of material and product components play a far from marginal role for the product development. Thus some suppliers can give impulses for the further development of low-tech products due to their special knowledge of materials, production possibilities etc.

In addition, service providers with specialised knowledge occasionally play an important role within the context of innovation activities. In this regard one can, for instance, mention design companies which assume responsibility for parts of the product design, or firms or institutes which have special competencies and facilities for quality tests or special technical development questions at their disposal. Sometimes specialised research institutes are also assigned development tasks such as, e.g., material testing. They furnish the aforementioned additional scientific knowledge necessary for low-tech innovations. Lastly, the companies occasionally draw on consultants, for instance, for solving problems of process development and optimisation. Altogether, the forms of exchange between the different actors of the distributed knowledge base can be very varied.

\subsection{Innovative capability}

The outlined knowledge base is without question necessary for the innovation capability of companies. It largely determines the direction and the scope of the innovation activities, insofar as it determines the scope of action for the companies which can only be surmounted with difficulties. On the one hand, accumulated knowledge bases naturally cause a high degree of inertia with regard to the direction of innovative action, on the other hand they largely determine the orientations and expectations prevailing in companies regarding possible and viable innovation perspectives, thus influencing the company's ability to assess, to adopt and to integrate new, external knowledge into the given knowledge base. This phenomenon-discussed as the "absorptive capacity" of companies in innovation research (cf. Cohen and Levinthal, 1990)- plays a central role especially in LMT companies: Unlike high-tech companies with their R\&D departments, low-tech businesses only have limited capacities, e.g. in the form of surplus knowledge resources, for the use and integration of new knowledge. Moreover, this problem becomes especially virulent if it concerns smaller companies with their already limited resources. A general consequence arising from this is the high path dependency of such companies which possibly hinders their development opportunities.

However, the way in which the companies actually use their available knowledge, is the point of decisive importance for their actual innovation ability. Following David Teece et al., this ability can be conceived as dynamic capability (Teece and Pisano, 1994; Teece et al., 1997).What is meant is the capability which enables the companies to cultivate and develop their knowledge base strategically, to mobilise it and, in doing so, to combine the individual knowledge elements in specific ways in order to generate technological innovations in the long run. It is generally assumed that this capability will be of great, even growing, importance in the light of turbulent and hardly predictable market and other environment conditions ${ }^{7}$.This unquestionably concerns development trends that are not only characteristic for high technology sectors but precisely also for the here examined LMT sectors with their pronounced competition situations.

If one looks at the findings regarding the innovation processes in LMT companies, one can discover a number of different dimensions pertaining to the dynamic capability:

- Firstly, it involves the ability to use and advance knowledge, which is in principle already available, in the context of product

7 For a discussion of the capability concept with regard to the issue of low-tech innovativeness particularly see Bender and Laestadius, 2005. 
and process innovations; it is a question of transforming this knowledge. In the afore-described type of the standard producer, this ability plays a decisive role regarding the gradual modification of specific product functions, for instance.

- Secondly, it concerns the capability continually to recombine available knowledge and technology elements in order to realise enhanced products and process structures. This ability is of particular importance, for example, in the case of the serviceoriented type of company described earlier on. Here existing product modules are constantly reassembled to new product variants.

- Thirdly, a further dimension has to be addressed, the ability to integrate new knowledge. This relates to the fact that a number of the companies examined more or less continually take up new, generally externally generated knowledge - be it practical experience of the sales personnel about completely changed marketing conditions or research results from engineering science concerning new machining procedures or potential product materials - and integrate it into their existing knowledge base, consequently developing new products and processes on this enhanced base.

The question concerning the conditions which affect this dynamic capability of companies, can again be answered with reference to the findings of innovation research.According to these, one can basically start from the assumption that this ability is strongly embedded in the practices and processes of the company organisation (cf. Henderson and Clark, 1990: 15). To begin with, the internal organisation practises unquestionably have a vital stake in this matter. As outlined above, innovations in very many cases proceed within the context of the operative processes, however, the strategies pursued in the individual cases may differ noticeably. In some cases, for instance, the management attempts to approach product and process innovations strategically by defining development projects with a certain priority and setting up target agreements together with the few engineers and master craftsmen in its staff. In other cases such as, e.g., those of fashion-oriented clothing manufacturers, procedures to generate product ideas within the context of the ongoing production process itself, have established themselves relatively well in the course of the years. In addition, there are also many cases in which innovation ideas resulted more by chance due to trial-and-error processes. Furthermore, they could oftentimes be ascribed to the ideas of individual managers, technicians or salespersons. Thus aspects such as sufficiently open channels of communication, some room to maneuver and specific slack times at least for certain employees, but also corresponding impulses and targets on the part of the management can be regarded as fundamental conditions promoting the target-oriented mobilisation of the available knowledge.

\subsection{Networks and Interrelationships with High-Tech Sectors}

In addition to the aforementioned conditions, management and the co-ordination of network relations between companies naturally are of great and growing importance for the companies' dynamic capability. As already outlined, this especially concerns the systematic use of organisationally distributed knowledge elements in the context of a differentiated knowledge base. On the one hand, it is actually a matter of integrating a company into a cross-company co-operation within the framework of a differentiated value chain. On the other hand, it concerns taking up the potentials of local and regional location factors. Generally speaking, an essential precondition for the efficiency of such relations is that the respective companies' organisational structure be geared to the demands of cross-company co-operation with, for instance, corresponding channels of communication, gateways and personnel responsibilities. In this respect, the professionalism of the respective managements is often a vital aspect. They must be able to harmonise and to control the specific competencies and the corresponding interests of many different co-operation partners in such a way that the transfer of the required knowledge is warranted.

In this context the relationship of low-tech to high-tech sectors are of decisive importance for the innovativeness of LMT companies. However, as the research findings show, technological flows do not move only from new and higher-technology sectors to older and lower-technology sectors. The analysis of the interrelationships between LMT companies and high-tech companies within value chains clearly show the strategic role LMT companies play for innovation in high-tech. In different cases it could be recognised that LMT companies actually boost the innovative capabilities of high-tech firms. In the case of a German paper producing company, a typical process specialist, the main impulse for innovation comes from the paper manufacturer's request that the chemical supplier, a high-tech company, should either alter an already existing product or develop a new one (e.g. a new dye). Furthermore, it can be emphasised that in many cases the viability of high-tech sectors and the levels of resources devoted to research and development are directly related to the rate of diffusion because the main customers for high-tech products are in the LMT sectors, and therefore the rates of return to $R \& D$ in high-tech areas are a direct function of rates of technological diffusion. 8

8 This aspect is discussed in more detail in Robertson and Patel, 2007. 
Generally, future industrial development in Europe does not depend on making a choice between high-tech and LMT industries. Rather, the performance of all these sectors is inextricably linked. On the one hand the productivity of LMT sectors is based on high-tech innovations, but on the other, the innovative capability of the high-tech sectors depends on their narrow relationship with LMT industries.

\section{Policy Issues}

In conclusion, the question raised at the outset should be taken up again, namely whether LMT companies and sectors should be incorporated into innovation policy considerations much more strongly than before and whether one should conceive measures to foster their innovative capability. On the basis of the aforementioned research findings as well as more generally oriented considerations, one can identified a number of significant factors and problem situations concerning innovation policy for LMT sectors. The main argument is that the term LMT is misleading since LMT companies are in a specific way innovative and they are a central element in the industrial innovative process in general. 9

\section{I Limited Awareness of LMT Industries}

Referring to the EU in general, the empirical findings show that there is little if any awareness of innovation-generating policies other than those focusing on R\&D. Correspondingly, the LMT sectors receive little attention from innovation policy makers on different levels, such as the EU, the national state and the regions. Therefore, a key policy task is to support activities and measures raising the awareness of low-tech industries and their specific needs and conditions. A fundamental precondition for this is the development of a new and broad understanding of innovation and the insight that one should no longer equate innovative ability with R\&D activities alone. Such intensification might include the establishment by the EU of a mechanism to closely investigate the needs of LMT firms so as to identify ways of supporting innovativeness. Whatever means are identified to provide support must be flexible enough to correspond to the objective and cultural needs of the recipients.

A further fundamental prerequisite is a holistic view of industrial innovation processes and the relevant interlocking of different kinds of knowledge as well as of the different elements of the companies' capabilities which enable them to be innovative and profitable. The policy conclusion to be drawn would therefore be that it is necessary to focus on the industrial innovation chain as a whole, to concentrate more strongly on inter-sectoral connections and to make a point of finding the potentials of LMT industries.

However, it must also be emphasised that the firms themselves have a low level awareness of innovation policies for LMT industries and that policy measures are perceived very differently by different firms. The policy measures that are regarded as helpful by some firms as a rule concern general aspects such as national policies providing tax incentives and subsidies for various activities and EU policies such as the Framework Programmes and Eureka. On the whole though, one can state that there are great innovation policy shortcomings as far as the specific problem situations of LMT com-panies are concerned.

\subsection{Knowledge and Company Capabilities}

As for the knowledge base, low-tech innovations presuppose the availability of specific practical in-house knowledge as well as the integration and use of complex knowledge inputs within networks and from high-tech sectors. It is therefore an important policy task to conceive measures and to support activities which aim at improving the knowledge base and the capability of LMT companies. This task can be realised at both the level of EU-wide support programs and also at national and regional levels. In practice, such measures should be directed at promoting the different dimensions of and particularly the preconditions for the capabilities of companies; especially the organisational conditions and management skills regarding a more efficient use of existing knowledge should be further developed.

\subsection{Networks}

Policy tasks should focus on the development of the companies' organisational structure so that they are geared to the demands of cross-company co-operation with corresponding channels of communication, gateways and personnel responsibilities. In this respect, the professionalism of management of LMT firms should be supported and further developed. Another important policy task is to concentrate on improving the firms' capabilities for making the right strategic choice as regards the dilemma between globalisation and local embeddedness. The empirical findings show the importance of a balanced dynamic between global, local and regional policies that operate in all sets of "environments" to which a firm may belong; the aim of policies at different levels to create infrastructure supporting the innovation process must facilitate this balanced dynamic. Clusters and fragmented economies need strong intermediate institutions and institutional infrastructure to pro-

${ }^{9}$ For the following particularly see Jacobson and Heanue, 2005. 
vide appropriate local conditions. To set up such institutions, the positive combination of the vision of public bodies and the interests of the stakeholders (i.e. collective actors) are important factors.

\subsection{Relations of LMT with High-Tech}

A key policy question underlying the PILOT project was whether innovation policy should focus on so-called high-technology or science-based industries in attempting to solve growth and employment problems, or whether it should look to the growth prospects within the low- and medium- technology industries on which the economy of developed countries is actually based. An important argument is that the policy issue is not a choice between these apparent alternatives.

It can be shown that the vast majority of output and employment in modern economies is accounted for by both manufacturing and service LMT sectors. Such sectors are also significant users of the output from high-tech sectors. In a modern economy, the levels of performance of both high-tech and nonhigh-tech sectors are heavily interdependent, and policy should view the economy as a whole.As a result, the promotion of the 90 percent of the economy that is made up of LMT sectors also promotes the welfare of the high-tech sectors (cf. Robertson and Patel, 2007).As a corollary, policies need to ensure that they encourage both the generation of knowledge and its diffusion, and that both operations are carried out at high velocity to maintain competitive advantage.

Summarizing the arguments: The focus on the contribution of LMT industries to the innovativeness of industry as a whole is extremely important in a policy perspective, both at national and regional levels. It is indispensable for developing a proper foundation for the overall growth and performance possibilities of the economy. Following the above line of argument, the high-tech prospects of many economies are based on the presence of and dynamic interaction with reliable low-tech functions and processes. Again, the term "low-technology" is misleading concerning the innovativeness of these sectors as well as concerning its relevance for industrial innovativeness in general.

The significance of LMT companies must ultimately also be seen against the background of the strong and probably increasing international competition pressure on complex technologies and products too. Their market position can by no means be regarded as permanently stable and promising. High technologies and the corresponding know-how are potentially ubiquitously available under the terms of the global economic integration. And the crucial point is, they are also quickly utilisable for innovations, so that the window for realising innovation profits is quite small. One instructive example, as experts stress, is that a developing country like China will in some years be one of the largest developers and producers of high-tech products such as mobile phones.Another example is the situation of the hightech automotive industry in a country like Germany. It is occasionally pointed out that the German in-dustry's dependency on the auto industry not only holds specialisation advantages but also brings the danger of severe competition with it since highly sophisticated cars are increasingly being produced more cheaply in newly industrialised countries. The policy conclusion to be drawn would therefore be that it is necessary to focus on the industrial innovation chain as a whole, to concentrate more strongly on intersectoral connections and to make a point of finding the potentials of low-tech industries. Most notably, the empirical findings show that there are favourable development potentials for low-tech indus-tries, definitely also in the hightech-oriented countries of the European Union.

\section{References}

BENDER, G.; Laestadius, S. (2005). Non-science based innovativeness: on capabilities relevant to generate profitable novelty. In: Bender, G.; Jacobson, D.; Robertson, P. (eds.), Non-ResearchIntensive Industries in the Knowledge Economy. Special Issue of Perspectives on Economic, Political and Social Integration, Catholic University, Lublin/PL, pp. I23-170

BENDER, G.; Jacobson, D.; Robertson, P. (eds.) (2005). Non-Research-Intensive Industries in the Knowledge Economy. Special Issue of Perspectives on Economic, Political and Social Integration, Catholic University, Lublin/PL

COHEN, W. M., Levinthal, D. A. (1990). Absorptive Capacity: A New Perspective on Learning and Innovation. Administrative Science Quarterly, 35 (I), Pp. I28-I 52.

FAULKNER, W.; Senker, J.; Velho, L. (1995). Knowledge Frontiers, Oxford.

FOSS, N. (1997). Resources, Firms and Strategies - A Reader in the Resource-Based Perspective, Oxford.

HENDERSON, R. M.; Clark, K. B. (1990). Architectural Innovation: The Reconfiguration of Existing Product Technologies and the Failure of Established Firm. Administrative Science Quarterly, 35 (I), pp. 9-30

HIRSCH-KREINSEN, H.; Jacobson, D. (eds.) (2008). Innovation in Low-Tech Firms and Industries. Cheltenham: Edward Elgar (forthcoming) 
HIRSCH-KREINSEN, H.; Jacobson, D.; Robertson, P.L. (2006). “Low-Tech' Industries": Innovativeness and Development Perspectives - A Summary of a European Research Project. In: Prometheus, March, pp. 3-2I

JACOBSON, D.; Heanue, K. (2005). Policy conclusions and recommendations. In: Bender, G.; Jacobson, D.; Robertson, P. (eds.), Non-Research-Intensive Industries in the Knowledge Economy. Special Issue of Perspectives on Economic, Political and Social Integration, Catholic University, Lublin/PL, Pp. 259-4I6

KALOUDIS, A.; Sandven, T.; Smith, K. (2005). Structural change, growth and innovation: the roles of medium and low-tech industries 1980-2000. In: Bender, G.; Jacobson, D.; Robertson, P. (eds.), Non-Research-Intensive Industries in the Knowledge Economy. Special Issue of Perspectives on Economic, Political and Social Integration, Catholic University, Lublin/PL, Pp. 49-74

KLINE, S. J.; Rosenberg, N. (1986). An overview of innovation. In: Landau, R.; Rosenberg, N. (eds.), The Positive Sum Strategy - Harnessing Technology for Economic Growth,Washington, pp. 275-305

MASKELL, P. (1998). Learning in the village economy of Denmark: the role of institutions and policy in sustaining competitiveness. In: Braczyk, H.-J., Cooke, P., Heidenreich, M. (eds.), Regional Innovation Systems, London, Pp. 190-2I3

MENDONÇA, S.; Tunzelmann, von N. (2004). Brave old World: Accounting for "High-Tech" Knowledge in "Low-Tech" Industries. Paper presented at the DRUID's Summer Conference "Industrial Dynamics, Innovation and Development” Copenhagen, Denmark, June 14-16

OECD (1997). Proposed Guidelines for Collecting and Interpreting Technological Innovation Data - the Oslo Manual. Paris

OECD (2002). Frascati Manual. Proposed Standard for Surveys on Research and Experimental Development. Sixth revision, Paris

OECD (2005). Science, Technology and Industry Scoreboard 2005, Paris

PALMBERG, C. (200I). Sectoral patterns of innovation and competence requirements - a closer look at low-tech industries. Sitra Report Series No. 8, Helsinki

PENROSE, E. (1959). The Theory of the Growth of the Firm. 3rd ed., Oxford

PRAHALAD, C. K.; Hamel, G. ( 1990). The core competence of the corporation. In: Harvard Business Review. 68 (3), Pp. 79-9I
ROBERTSON, Paul L./Parimal R. Patel (2007). New Wine in Old Bottles - Technological Diffusion in Developed Economies. In: Research Policy, 36, pp. 708 - 721

ROBERTSON, P. L.; Smith, K. (2008). Technological Upgrading and Distributed Knowledge Bases. In: Hirsch-Kreinsen, H.; Jacobson, D. (eds.): Innovation in Low-tech Firms and Industries, Cheltenham (forthcoming)

SCHMIERL, K. (ed.) (2000). Intelligente Produktion einfacher Produkte am Standort Deutschland. Frankfurt/New York

TEECE, D. J.; Pisano, G. (1994). The Dynamic Capabilities of Firms: an Introduction. In: Industrial and Corporate Change, 3 (3), pp. 537-556

TEECE, D. J.; Pisano, G.; Shuen, A. ( 1997). Dynamic Capabilities and Strategic Management. In: Strategic Management Journal, I 8 (7), pp. 509-533

The Economist (1998). The strange life of low-tech America. October 17th, pp. 85-86

TUNZELMANN, von N.; Acha, V. (2005). Innovation in „LowTech“ Industries. In: Fagerberg, J.; Mowery, D.C.; Nelson, R.R. (eds.), The Oxford Handbook of Innovation, Oxford, pp. 407-432 